\title{
Organizational, technical and economic fundamentals of waste management and monitoring
}

\author{
Evgeniy Velichko ${ }^{1 *}$, Edward Tshovrebov ${ }^{2}$, Ural Niyazgulov ${ }^{3}$ \\ ${ }^{1}$ National Research Moscow State University of Civil Engineering (NRU MGSU), 26 Yaroslavskoye \\ sh., Moscow, 129337, Russia \\ 2 "Research Institute" Center for environmental industrial policy", 42, Olympic Ave., Mytishchi, \\ Moscow region, 141006, Russia \\ ${ }^{3}$ Russian university of transport (MIIT), d 9, p. 9 St. Obraztsova, Moscow, 127994, Russia
}

\begin{abstract}
The article deals with issues of monitoring, planning, organizational and technical support, economic regulation and improving the efficiency of the infrastructure for processing, recycling and disposal of waste, resource conservation and management of secondary resources, their use as secondary raw materials for production, services, work and power generation. The Russian Federation has significant potential for economic growth due to the efficient use of secondary resources from billions of tons of generated production and consumption waste annually. These ecologically unsafe anthropogenic objects can be characterized as a source of valuable renewable raw materials, material and fuel and energy resources. However, the scale and level of use of various types of secondary resources are characterized by considerable unevenness and depend on the demand for secondary raw materials, the resource value of the waste, the environmental situation arising from treating them as environmental polluters, on the real economic conditions that determine the profitability of each specific type. economic activities that use secondary resources for the manufacture of products, works, services, energy production. The methods of monitoring the industry for the treatment, disposal and disposal of waste are: information-analytical, information-statistical, sociological, geo-information. The legal status of the monitoring system of the industry for the treatment, disposal and disposal of waste is determined by the limitations of its functionality within the framework of the goals and objectives facing it.
\end{abstract}

\section{Introduction}

The problems of handling production and consumption wastes, ensuring the environmental safety of territories, resource conservation and the involvement of secondary resources in the economic turnover are particularly relevant in the era of a shortage of natural resources, the ever-increasing impact of toxic waste on the environment. These man-made objects are

* Corresponding author: pct44@yandex.ru 
a source of significant economic damage (environmental damage) caused to the natural environment and public health. One of the main reasons for Russia's lagging behind in terms of waste utilization, environmentally acceptable, technically feasible and economically feasible use of secondary material and energy resources is the lack of an economically efficient system for managing waste and secondary resources, including their separate collection, treatment, disposal and neutralization, and the involvement of waste fractions. in economic circulation, ensuring sustainable demand for products from secondary raw materials. [1-9].

\section{Problem statement}

Significant problems of Russia in the field of planning, organizing and regulating activities for dealing with secondary resources are associated with a lack of information on waste, including their composition, resource value, production possibilities of goods from them and other information.

The used form of federal statistical observation in the field of production and consumption waste handling No. 2-TP (waste) is mainly intended for obtaining balance accounting data and subsequent solution of environmental protection planning tasks based on them. There is no systematization of data on the movement of waste and in economic sectors in the territorial context - by the subjects of the Russian Federation, economic regions, industrial clusters. In general, the country does not summarize, or there is no objective data on waste treatment, infrastructure for their disposal and disposal, the territorial location of such industrial facilities; official statistical information on the indicators characterizing the development of this infrastructure as a whole, technology, equipment, mechanisms, equipment and technical devices for processing, recycling, disposal of waste. It is not possible to collect and summarize any full-fledged reliable indicators on education, movement, use of secondary resources across Russia for making management decisions, regulatory impact, and economic evaluation of the circulation of secondary resources.

At the same time, the area of burial of hazardous waste at landfills and unauthorized landfills, as well as the accumulated environmental damage and economic damage from environmental pollution, increase annually [10].

All this leads to a deterioration of the environmental situation on a country scale and to a significant lag of Russia in the effective use of the economic growth reserve, and an increase in GDP due to the use on an industrial scale of valuable secondary materials, while maintaining the strategic reserve of non-renewable resources: minerals, natural waters, forest fund.

In the EU countries, the USA and Japan, legal instruments have been created for several decades now to organize an effective system of regulation, monitoring of waste and secondary resources, as well as economic conditions for the most technically and technologically possible level of utilization (recycling, recovery, regeneration) of industrial and household waste, the involvement of secondary resources in economic activities with the achievement of high levels of profitability of production and products from recycled materials [11-20].

For the first time in the entire more than 25-year period of development of modern Russia, the Strategy for the Development of Industry for the Treatment, Disposal and Disposal of Production and Consumption Wastes for the Period up to 2030 was adopted as an innovative basic document in the resource-saving and waste-processing sphere. The document on sectoral strategic planning provides for the creation of a de facto new industrial infrastructure; about the block of new tasks of a resource-saving and wasteprocessing orientation, the use of valuable secondary resources from the generated waste 
throughout the country as one of the reserves of economic development.

In connection with the aforementioned long-term plans, an urgent problem arises in creating a unified accounting system throughout the country, monitoring the circulation of secondary resources, planning and ensuring the economic efficiency of resource-saving technologies, and measures in industrial and other sectors and sectors of the economy. This system should become one of the effective mechanisms for the creation and development in Russia of an innovative high-tech infrastructure for the treatment, utilization, and disposal of industrial and consumption waste as part of the Strategy adopted by the Government of the Russian Federation.

The methods of scientific research in this work are based on the use of factor, comparative, expert types of analysis.

\section{Discussion}

A group of scientists and specialists of the FSAI "Research Institute" Center for Environmental Industrial Policy ", with the participation of the scientific potential of the Moscow State Construction University, the Department of Geodesy and Geoinformatics of the Moscow State University of Communications for a number of years, work is underway to create a conceptual framework and methodological foundations for planning, organizing, implementing monitoring in the field of waste management and secondary resources.

According to the results of the research, publications, discussions at international, AllRussian conferences, meetings, proposals were developed for a methodological substantiation, law enforcement of the concepts in the relevant field considered in this work.

It is proposed to define the monitoring of the industry for the treatment, utilization and disposal of waste as a comprehensive system of continuous monitoring of the formation and state of the industry in this area, a forecast of its future development, including a scientifically based comprehensive, comprehensive, objective analysis and assessment of indicators.

This type of monitoring should be considered as one of the principles of industrial policy implemented for the implementation of the objectives defined by the Federal Law "On Industrial Policy in the Russian Federation": the formation of a high-tech, competitive industry ensuring the transition of the state economy from raw materials to the innovative type of development and in fulfillment of the objectives industrial policy, including:

- stimulation of stakeholders in the industry rational and efficient use of material, natural resources, to ensure the introduction of import-substituting, resource-saving and environmentally friendly technologies;

- the creation and development of modern industrial infrastructure, infrastructure support activities in the industry, consistent with the goals and objectives defined by the strategic planning documents at the federal level.

Monitoring of the industry for the treatment, recycling and disposal of waste serves as a mechanism for implementing the main objectives of the Industry Strategy for processing, recycling and disposal of industrial and consumer waste for the period up to 2030, in particular:

- formation of an effective integrated management and regulation system in the field of processing, utilization and disposal of industrial and consumer waste;

- creation and expansion of the national industrial industry and infrastructure for processing, utilization, disposal of industrial and consumer waste, use of waste as a secondary raw material for the production of new products based on the modernization and technical re-equipment of existing production and technical complexes, the creation of new innovative industrial production; 
- the creation and expansion of the Russian industrial and technological base, which provides the domestic industry of processing, recycling and disposal of waste with modern Russian high-tech competitive, environmentally friendly equipment, machinery, machines and mechanisms with high export potential;

- the formation and future development of the sectoral scientific-technical and information-analytical infrastructure in the field of waste treatment, utilization and neutralization, resource saving.

By its nature and in accordance with the principles and priorities laid down in waste treatment, monitoring in this area should ensure the implementation of the following objectives:

- centralization, automation, optimization of the collection and processing of information necessary to ensure the implementation of industrial policies in the field of resource conservation and the use of secondary resources within the framework of the powers of the Ministry of Industry and Trade of Russia to support and encourage activities to involve secondary resources in the economic turnover, resource saving, treatment, disposal waste, import substitution, creation and prospective development of domestic technological and engineering base providing the industry with modern high-tech equipment with high export potential, as well as to increase the efficiency of information exchange on the state of the industry and its development forecast;

- information and analytical support of management decisions during the formation of a system of integrated accounting, regulation of the treatment of industrial waste and secondary resources and its subsequent effective functioning at the federal and regional levels.

Taking into account the goals set, the functions of the integrated monitoring system of the industry for the treatment, recycling and disposal of waste may be:

- collection, processing, systematization, analysis, provision of complete, current and verified information on the amount of treated, recycled, neutralized waste based on integration with existing federal statistical and other accounting systems;

- collection, processing, systematization, analysis, the provision of complete, relevant and verified information on the treatment, including the use of secondary material and energy resources for the production of goods, the performance of work, the provision of services, the production (generation) of energy;

- creation and maintenance of an information base on economic entities producing equipment, machinery, machines, and mechanisms for the waste treatment, recycling, and disposal industry;

- formation and maintenance of information base on the best available technologies in the field of resource conservation, the use of secondary resources, treatment, disposal and disposal of waste;

- creation and maintenance of an information base on legal entities and individual entrepreneurs, whose economic activities are related to the treatment, disposal, waste disposal, use of secondary resources, using low-waste technologies and secondary raw materials in technological processes;

- integrated search and visual cartographic presentation of information on the entire functionality of an integrated industry monitoring system, incl. assessment and visualization of a set of balance sheet indicators reflecting circulation, use of secondary resources in industry, federal and regional formats.

In this case, the users of this system are: federal and regional government bodies, the State Industry Information System, local governments, legal entities and individual entrepreneurs, scientific organizations and institutions, public associations, the media, citizens.

The methods of monitoring the industry for the treatment, disposal and disposal of 
waste are: information-analytical, information-statistical, sociological, geoinformation (Figure 1).

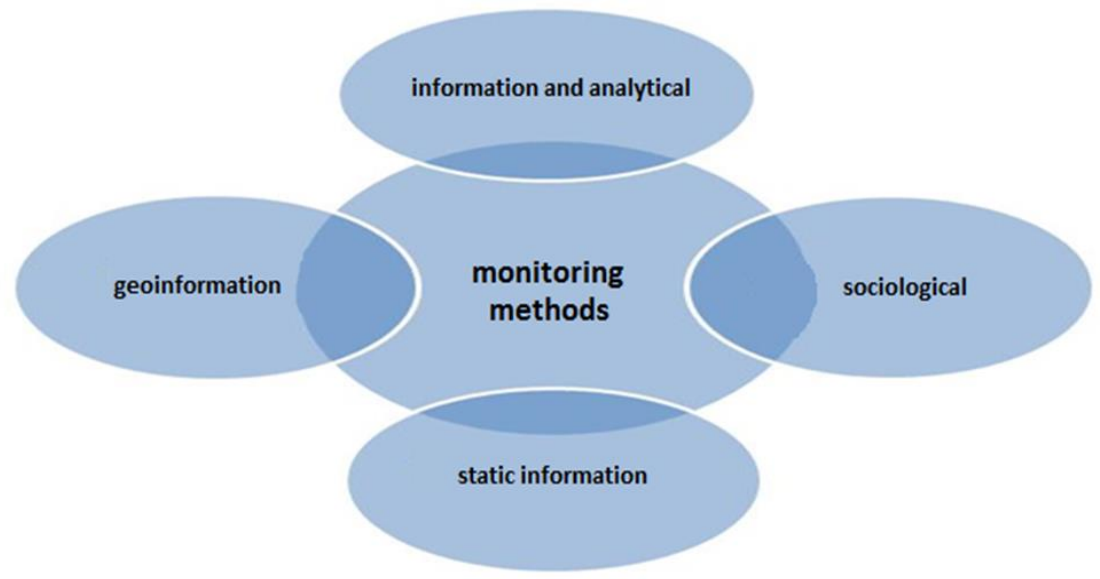

Fig. 1. Methods of monitoring the industry for recycling, disposal and disposal of waste.

The legal status of the monitoring system of the industry for the treatment, disposal and disposal of waste is determined by the limitations of its functionality within the framework of the goals and objectives facing it. The tasks of this system should not include state environmental monitoring (state environmental monitoring) - environmental monitoring carried out by state authorities of the Russian Federation and constituent entities of the Russian Federation in accordance with their competence (compiling, maintaining information on statistical reporting No. 2-TP (waste), collection of information, analysis and assessment of places, sources and quantities of collection, accumulation, transportation, storage and disposal of waste, MSW landfills, ecologically and technically Asna production, monitoring the implementation of territorial schemes for dealing with MSW, etc.), monitoring in the field of transport infrastructure, sanitary and hygienic monitoring, organized and carried out in accordance with regulatory legal acts their competence.

\section{Results}

Taking into account the full-fledged, objective, reliable monitoring data, it is advisable to carry out planning and economic evaluation of the distribution of various infrastructure facilities for the future, on the basis of an assessment and analysis of the following indicators:

- the types and quantities of production and consumption waste, as well as the level of their environmental hazard;

- industrial specificity and concentration of production of industries of the economy on a territorial basis;

- indicators of output in the sectors of the Russian economy for the period up to 2030 under various scenario conditions;

- standards for waste generation per unit of output;

- the possibility of using waste as secondary resources;

- state and level of use of existing facilities for processing, recycling and disposal of waste;

- the purpose and technological equipment of the enterprises of the industry for the 
treatment, recycling and disposal of waste;

- state and prospects of development of road and transport infrastructure facilities (throughput and carrying capacity of roads and railways, performance indicators of depot, stations, bus stations, bus stations);

- ecological and sanitary-epidemiological situation;

- economic conditions (markets for products from secondary raw materials, the level of economic development of industries and sectors of the regional economy, etc.);

- rates of social and economic development and other factors.

This system will increase the efficiency of the waste management system by $20-30 \%$.

\section{Conclusions}

Further development and improvement of monitoring, regulation, management, planning systems, as well as optimization and improvement of economic, organizational and technical activities in the field of waste management and secondary resources will help ensure a strategic course for energy and resource saving, saving irreplaceable natural resources and sustainable development of all sectors and sectors of the economy, addressing current environmental challenges currently facing $d$ by the Russian state, the successful implementation of the planned industrial development strategies for processing, recycling and disposal of industrial and consumer waste.

\section{References}

1. V. Isakov and E. Tshovrebov For Legal framework environmental protection (Moscow: MOF MOSU MVD of Russia) (2004).

2. E. Tshovrebov ECOS 3 13-19 (2008)

3. M.S. Bani, Z.A. Rashid, K.H.K. Hamid World Academy of Science, Engineering and Technology. 25, 161-168 (2009)

4. E. Tshovrebov Bul. Of the Kost. St. Univ. 3 10-14 (2013). DOI: 10.22227/19970935.2018.11.1326-1340

5. E. Tshovrebov Environmental protection in railway transport (Moscow: Kosmosinform) (1994)

6. R. Kuprin, E. Tshovrebov and U. Niyazgulov Qual. Innov. Educ. 2 62-70 (2018)

7. P. Chepiga Probl. Of. Mod. Econ. 4(36) 45 (2010)

8. G. Nikitin, V. Osmakov and D. Skobelev Comp. 3(144) 29-33 (2017)

9. E. Tshovrebov and E. Velichko Vest. MGSU 9 95-110 (2015). DOI: 10.22227/19970935.2015.9.95-110

10. E. Tshovrebov and S. Sadova Vest. RANS 2 57-59 (2014)

11. Murray R Greenpeace Environmental Trust (London), (2002)

12. David H. F. Liu, Béla G. Lipták and Paul A. Bouis Hazardous waste and solid waste (Boca Raton: Lewis), (2000)

13. S.R. Rao Resource recovery and recycling from metallurgical wastes (UK: Oxford), (2006).

14. J. Antrekowitsch and S. Steinlechner JOM 63(1) 68-72 (2011). DOI: 10.1007/s11837011-0017-2 
15. M. Mazzanti and R. Zoboli Resources, Conservation and Recycling. 52 (10). 12211234 (2008). DOI:10.1016/j.resconrec.2008.07.003.

16. S. Dimitris and D. Achilias Material Recycling - Trends and Perspectives (InTech) (2012). DOI:10.5772/2003

17. J. Hart, K. Adams, J. Giesekam, D. Tingley, and F. Pomponi, Procedia CIRP. 80, 619624 (2019). DOI: 10.1016/j.procir.2018.12.015.

18. J.C. Powell Waste Man. And Res. 14(6), 515-526 (1996). DOI: 10.1177/0734242X9601400601.

19. D.Marković, D. Janošević, M. Jovanović and V. Nikolić Fact. Univ. Ser.: Man. And Res. 14113 (2010)

20. B. Vahdani, R. Tavakkoli-Moghaddam, A. Baboli and S. Mousavi, World Academy of Science, Engineering and Technology. 78. 45-49 (2013). DOI: 10.5281 /zenodo. 1058295 . 